\title{
The Impact of Cooking of Beef on the Supply of Heme and Non-Heme Iron for Humans
}

\author{
Gille Gandemer1, Valérie Scislowski², Stéphane Portanguen ${ }^{3}$, Alain Kondjoyan ${ }^{3 *}$ \\ ${ }^{1}$ Division Sciences and Process Engineering of Agricultural Products, INRAE (Institut National de Recherche Pour l'Agriculture, \\ l'Alimentation et l'Environnement), Nantes, France \\ ${ }^{2}$ ADIV (Viande Performance), Clermont-Ferrand, France \\ ${ }^{3}$ UR370 QuaPA, INRAE (Institut National de Recherche Pour l'Agriculture, l'Alimentation et l'Environnement), \\ Saint-Genès-Champanelle, France \\ Email: *alain.kondjoyan@inrae.fr
}

How to cite this paper: Gandemer, G., Scislowski, V., Portanguen, S. and Kondjoyan, A. (2020) The Impact of Cooking of Beef on the Supply of Heme and Non-Heme Iron for Humans. Food and Nutrition Sciences, 11, 629-648.

https://doi.org/10.4236/fns.2020.117045

Received: June 5, 2020

Accepted: July 6, 2020

Published: July 9, 2020

Copyright $\odot 2020$ by author(s) and Scientific Research Publishing Inc. This work is licensed under the Creative Commons Attribution International License (CC BY 4.0).

http://creativecommons.org/licenses/by/4.0/

\begin{abstract}
Red meat contains a high proportion of heme iron (HI) which is absorbed at a far higher extent into the blood than the non-heme iron (NHI) found in plants. However, $\mathrm{HI}$ and $\mathrm{NHI}$ are expelled in the juice during cooking while a fraction of $\mathrm{HI}$ is converted into $\mathrm{NHI}$, thus decreasing iron bioavailability. This paper relies on experiments and the use of modeling. The kinetics of the conversion of $\mathrm{HI}$ into NHI was measured and modeled in juice extracted from uncooked beef meat, and beef cubes were cooked to measure the variations of $\mathrm{HI} / \mathrm{NHI}$ contents. In meat, $\mathrm{HI} / \mathrm{NHI}$ ratio decreased from 2.0 when it was raw to less than 1.0 for the longest heat treatments and highest temperatures. The model was used to predict the effect of cooking conditions on the variations of the iron supplied by beef meat. The lowest contribution of meat to iron supply was found for under-pressure cooking at temperatures above $100^{\circ} \mathrm{C}$.
\end{abstract}

\section{Keywords \\ Iron, Model, Meat, Transfer, Reaction}

\section{Introduction}

Iron deficiency is identified as the most common nutritional problem in the world, affecting several billion people, mainly children, pregnant women and women of child-bearing age, both in developing countries and in Europe [1] [2] [3]. Iron deficiency can increase the mortality and morbidity of both mother and child at birth [4], decrease the mental and psychomotor development of children [5] and alter work performance and resistance to infection [6]. 
In humans of normal status, iron absorption is higher when meat is part of the diet for at least 3 reasons. Firstly, red meat supplies high amounts of iron, mainly HI as myoglobin. Secondly, far more HI is absorbed than NHI (15\% - 40\% versus $2 \%-10 \%$ ) [7]-[12]. Thirdly, meat favors NHI absorption, through the so-called "meat factor" which could be related to cysteine-containing peptides arising from muscle protein hydrolysis in the intestines [13] [14]. In contrast, NHI in the absence of the meat factor is poorly absorbed because many components of diets such as tannins and polyphenols inhibit its absorption [15] [16] [17]. Several descriptive models (statistical or compartmental) have been developed to predict iron bioavailability in various diets [12] [18] [19]. One of the main parameters affecting the quality of prediction is the $\mathrm{HI}$ content in diets and the changes in both HI and NHI content during cooking [12].

Red meats from beef, horse, and lamb generally contain high amounts of iron and especially HI. The effect of animal species and muscle type on HI and NHI contents has been reported in details in the literature [20]-[25]. In contrast, the effects of meat cooking on HI and NHI contents are less documented and much information is lacking (Table 1). It has been established that heating causes changes in $\mathrm{HI}$ and $\mathrm{NHI}$ contents in meat through several mechanisms. First, part of $\mathrm{HI}$ and NHI is expelled into the juice during cooking [26]. Second, heating over $60^{\circ} \mathrm{C}$ induces the progressive denaturing of globin, which leads to an increase in insoluble HI in meat and juice [27] [28]. Third, part of HI is converted into NHI during meat cooking through oxidation of the porphyrin ring [23] [26] [29]. The relative contributions of these phenomena to iron cooking losses depend on many parameters including the type of cooking equipment, functioning, and control, the time-temperature treatment chosen, and meat cut geometry

Table 1. Effect of different cooking modes and conditions on the cooking yield, the HI and NHI contents, and on the HI/NHI ratio measured in literature for meat. Cooking yield is based on the variations of the sample weights recorded in the literature papers (ratio of the mass of the cooked meat piece to the mass of the raw meat piece multiplied by 100). The percentages of iron, of $\mathrm{HI}$, and $\mathrm{NHI}$ contents are calculated by $100 C_{\mathrm{Fe}} /\left(C_{\mathrm{Fe}}\right)_{\mathrm{raw}}, 100 C_{\mathrm{HI}} /\left(C_{\mathrm{HI}}\right)_{\mathrm{raw}}, 100 C_{\mathrm{NHI}} /\left(C_{\mathrm{NHI}}\right)_{\text {raw }}$ respectively.

\begin{tabular}{|c|c|c|c|c|c|c|c|c|c|c|c|}
\hline & & & & \multicolumn{3}{|c|}{ Iron (mg/g DM) } & \multicolumn{3}{|c|}{$\begin{array}{c}\% \text { of iron content calculated } \\
\text { on the raw meat basis }\end{array}$} & \multirow{2}{*}{$\begin{array}{c}\text { Ratio } \\
\text { HI/NHI }\end{array}$} & \multirow{2}{*}{ References } \\
\hline \multicolumn{2}{|c|}{ Cooking modes } & Pieces size & Cooking yield (\%) & \multirow{2}{*}{72.1} & \multirow{2}{*}{$\begin{array}{c}\text { HI } \\
57.1\end{array}$} & \multirow{2}{*}{$\begin{array}{l}\mathrm{NHI} \\
15.0\end{array}$} & \multirow{2}{*}{$\begin{array}{c}\text { Total } \\
100\end{array}$} & \multirow{2}{*}{$\begin{array}{l}\text { HI } \\
100\end{array}$} & \multirow{2}{*}{$\begin{array}{c}\text { NHI } \\
100\end{array}$} & & \\
\hline Raw & / & \multirow{3}{*}{$\begin{array}{l}\text { LD Steack }(2 \mathrm{~cm} \text { in } \\
\text { thickness })\end{array}$} & 100.0 & & & & & & & 3.8 & \multirow{4}{*}{ [21] } \\
\hline Grilled & & & 75.9 & 69.8 & 51.2 & 18.6 & 97 & 90 & 124 & 2.8 & \\
\hline Pan fried & Core $\mathrm{T}^{\circ}: 70^{\circ} \mathrm{C}$ & & 74.5 & 70.1 & 47.6 & 22.5 & 97 & 83 & 150 & 2.1 & \\
\hline Roasted & & $0.500 \mathrm{~kg}$ & 71.6 & 69.5 & 46.2 & 23.3 & 96 & 81 & 155 & 2.0 & \\
\hline Raw & I & I & 100.0 & 83.9 & 56.9 & 28.5 & 100 & 100 & 100 & 2.0 & \\
\hline $60^{\circ} \mathrm{C}$ & Immersed in & ST Steak $2.5 \mathrm{~cm}$ in & 76.9 & 72.5 & 41.8 & 31.1 & 86 & 73 & 109 & 1.3 & \\
\hline $77^{\circ} \mathrm{C}$ & Water bath & thickness $(0.160 \mathrm{~kg})$ & 65.1 & 69.7 & 37.5 & 31.6 & 83 & 66 & 111 & 1.2 & {$[26]$} \\
\hline $97^{\circ} \mathrm{C}$ & for 1 hour & beef and pork & 55.9 & 79.6 & 41.8 & 37.6 & 95 & 73 & 132 & 1.1 & \\
\hline Autoclave & $60 \mathrm{~min}$ & $\begin{array}{c}2.5 \mathrm{~cm} \text { in thickness } \\
(0.160 \mathrm{~kg})\end{array}$ & 52.3 & 69.2 & 28.9 & 36.2 & 82 & 51 & 127 & 0.8 & \\
\hline
\end{tabular}


and size [23] [24]. Comparing the data on the quantification of iron losses and iron conversion is often difficult because measurements are performed on meat cuts of different shapes and sizes that are heated using various cooking modes and under different time-temperature conditions.

The application of experimental designs will always be limited to compensate for the lack of literature whereas combining modeling and experiments is a good way to better understand the respective effects of the different reactions and mechanisms observed experimentally and to predict non-measured data [30]. The purpose of this paper is to describe a method to improve the prediction of both $\mathrm{HI}$ and $\mathrm{NHI}$ losses in meat pieces due to juice expulsion and to the conversion of HI into NHI by the development of a mathematical combined heat-mass transfer and reaction model. This model, often mentioned in the following as "the transfer-reaction model", is used at the end of the paper to discuss the effect of cooking mode and time-temperature conditions on the iron supply for consumers of beef meat.

\section{Approach, Experimental Procedure and Mathematical Model}

In the first step, the reaction kinetics of the thermal conversion of $\mathrm{HI}$ into NHI was measured in meat juice and modeled under a wide range of time-temperature conditions. Then meat cubes were cooked in a water bath to determine the variations of the HI and NHI contents due both to juice expulsion and to thermal conversion. During experiments, the heating of the samples was most of the time continued well beyond the usual cooking durations to be able to test the robustness and accuracy of the numerical model under these extreme conditions.

\subsection{Experiments}

\subsubsection{Meat Samples}

The meat came from muscles of 2 - 3-year-old Charolais cows, vacuumpacked and then aged for 12 days at $4^{\circ} \mathrm{C}$. Two muscles were used: longissimus thorasis and semimembranosus (named in the following LT and SM respectively). The $\mathrm{pH}$ was about 5.5. Muscles were frozen at $-80^{\circ} \mathrm{C}$ until the experiments were performed. Before the experiments, the meat was thawed at $4^{\circ} \mathrm{C}$ for 48 hours and then cut into appropriate pieces to extract juice or to be cooked. Meat remaining after cutting was used to determine the initial contents of $\mathrm{HI}$ and NHI in raw meat. The dry matter contents of the samples ranged from $22 \%$ to $25 \%$ while the fat content ranged from $3 \%$ to $5 \%$.

\subsubsection{Measured Kinetics of the Conversion of $\mathrm{HI}$ into $\mathrm{NHI}$ in Meat Juice}

Juice was extracted from SM pieces about $300 \mathrm{~g}(30 \times 50 \times 200 \mathrm{~mm})$ according to the procedure of [31]. The pieces were frozen slowly to weaken the muscle cells through the formation of large ice crystals and then thawed before the pressing stage. Juice was extracted through three successive steps under 300 bars (the muscle sample was folded and placed again in the device to be squeezed 3 
times) using a hydraulic press and a specific device to maintain the muscle (Figure 1). Juices were collected, filtered on a sintered glass under a low vacuum and then freeze-dried and stored at $-80^{\circ} \mathrm{C}$. Fresh juice accounted on average for $31 \%$ of meat weight and contained $10.2 \%$ of dry matter. To determine the kinetics, juices were restored to a final density of 1.022 in distilled water. An aliquot of juice $(15 \mathrm{~mL})$ was poured into a test tube, closed hermetically. Tubes were heated in the following conditions: $50^{\circ} \mathrm{C}$ for $7,20,40$ and $60 \mathrm{~min}, 60^{\circ} \mathrm{C}$ for 10 , 20,40 and $300 \mathrm{~min}, 80^{\circ} \mathrm{C}$ for $10,20,60,180$ and $300 \mathrm{~min}, 89^{\circ} \mathrm{C}$ for $10,60,180$ and $300 \mathrm{~min}, 98^{\circ} \mathrm{C}$ for $10,60,180,300$ and $900 \mathrm{~min}, 120^{\circ} \mathrm{C}$ for $10,60,180$ and $300 \mathrm{~min}$. To correctly determine the kinetics parameters, it was necessary that the measurements reflect the evolution of the reaction rates at the different temperature levels. As these rates were initially unknown, a step-by-step approach was applied to determine the most suitable measurement times for each of the temperature levels starting from the lowest temperatures. This step-by-step approach explains why the measurement times were sometimes different from one temperature level to another. Times of $900 \mathrm{~min}$ and even $300 \mathrm{~min}$ are much longer than those commonly used for cooking beef meat, but these long experimental times were needed to precisely determine the model's parameters to predict the conversion of HI into NHI. The tubes were heated in a water bath (up to $98^{\circ} \mathrm{C}$ ) or an oil-bath (for $120^{\circ} \mathrm{C}$ ). They were then cooled in ice-water until the

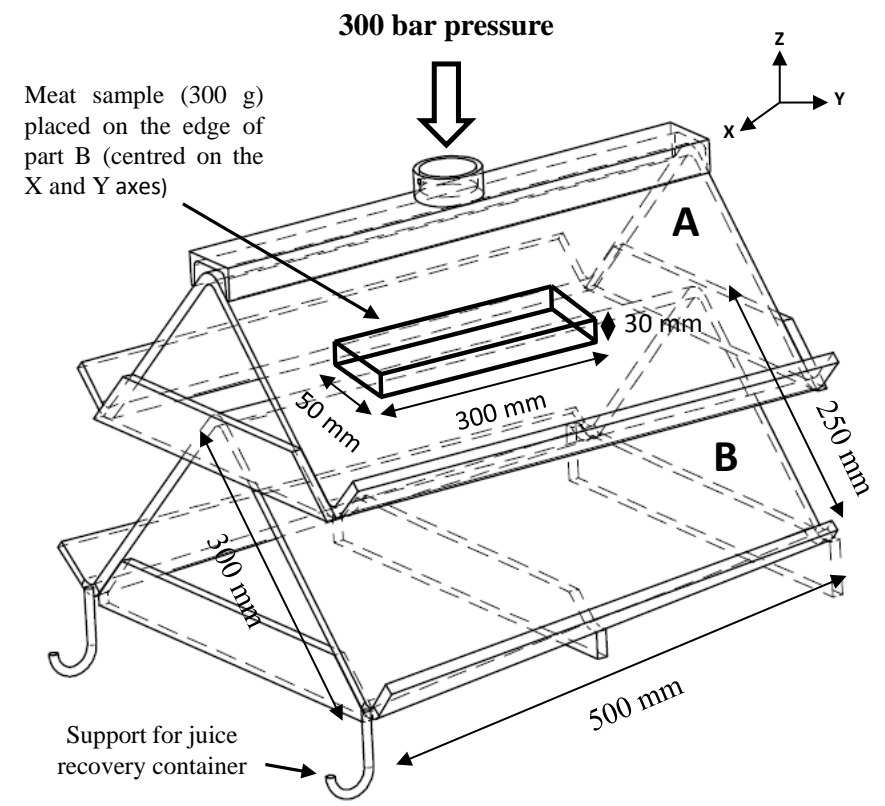

Figure 1. Schematic representation of the system of juice extraction (made in dichromate steel). This device is placed under a press generating a pressure of 300 bar (15 t). The meat sample is placed between parts A and B of the device as shown in the graph. Part B of the device has a slope of $10 \%$ which allows the juice to flow during pressing. During pressing, it is estimated that the surface area of the sample is multiplied by 5 (for an initial surface area of $150 \mathrm{~cm}^{2}$, the final surface area is about $750 \mathrm{~cm}^{2}$ ) but it remains much smaller than the total area of the part $B$ of the device that is greater than $2500 \mathrm{~cm}^{2}$. 
temperature fell to $4^{\circ} \mathrm{C}$. Four tubes were heated to establish each kinetics point. One was used to monitor the temperature kinetics in the tube with a thermocouple and the 3 others to measure the HI and NHI contents in meat juice after heating. HI and NHI contents were also determined in triplicate in freshly restored juice (from the juice freeze-dried).

\subsubsection{Measured Kinetics of HI and NHI in Meat Pieces}

Thawed pieces of LT were cut into small cubes: $30 \times 30 \times 30 \mathrm{~mm}$. Four cubes of meat were used for each point/time of the kinetics. One was used to measure the evolution of temperature in the sample and the three others for iron analyses after heating. Meat was heated in a water bath. The raw meat cubes were placed on racks and directly immersed in the water at $60^{\circ} \mathrm{C}, 80^{\circ} \mathrm{C}$ or $95^{\circ} \mathrm{C}$ for 60,180 , or $300 \mathrm{~min}$. Measurements were also performed after $30 \mathrm{~min}$ of heating at $80^{\circ} \mathrm{C}$ and $95^{\circ} \mathrm{C}$ to obtain a more accurate analysis of the kinetics. At the end of the heating time, the samples were quickly cooled in a freezer until the internal temperate fell to $4^{\circ} \mathrm{C}$. HI and NHI contents were determined in triplicate for each kinetics point to calculate the standard deviation.

\subsubsection{HI and NHI Measurements}

HI was determined after extracting heme in acidified acetone according to the method of [32]. Samples of meat $(2-4 \mathrm{~g})$ or juice $(4 \mathrm{~mL})$ were homogenized for 15 seconds with a polytron in acidified acetone mixture (acetone/water/pure $\mathrm{HCl}$ : 40/9/1). The samples were placed in the dark for 20 hours before centrifuging at $2200 \mathrm{rpm}$ for $10 \mathrm{~min}$. The supernatants were filtered on Whatman paper and the absorbance was measured at $640 \mathrm{~nm}$. The HI concentration was calculated using a standard curve made of hydrochloride-hemin in acidified acetone mixture.

NHI was determined using ferrozine as described by [23] and [33]. Briefly, samples of meat $(2-4 \mathrm{~g})$ and juice $(4 \mathrm{~mL})$ were mixed with 3 volumes of $0.1 \mathrm{M}$ citrate-phosphate buffer, $\mathrm{pH}$ 5.5. The samples were homogenized with a Polytron for several seconds. Then, $1 \mathrm{~mL}$ of $2 \%$ ascorbic acid in $0.2 \mathrm{~N} \mathrm{HCl}$ was added to $3 \mathrm{~mL}$ of homogenate and kept at room temperature for $15 \mathrm{~min}$. Next, $1 \mathrm{~mL}$ of $11.3 \%$ TCA was added to precipitate proteins. Afterward, the homogenate was centrifuged at $3000 \times \mathrm{g}$ for $10 \mathrm{~min}$ at room temperature. One $\mathrm{mL}$ of the supernatant was mixed with $0.8 \mathrm{~mL}$ of $10 \%$ ammonium acetate and $0.2 \mathrm{~mL}$ of ferrozine reagent. The absorbance was read at $562 \mathrm{~nm}$ against a blank. The NHI concentration was calculated using a standard curve made of $\mathrm{FeCl}_{2}$ in $0.1 \mathrm{~N} \mathrm{HCl}$ solution. Total iron was calculated by adding the HI and NHI contents.

The results were expressed as $\mu \mathrm{g} / \mathrm{g}$ dry matter in meat and $\mu \mathrm{g} / \mathrm{mL}$ in juice. Meat dry matter was determined by drying meat samples (about $2-5 \mathrm{~g}$ ) in an oven at $105^{\circ} \mathrm{C}$ according to the normalized method [34].

\subsection{Mathematical Transfer-Reaction Modeling}

The total model combined the calculations of the heat-mass transfer model pre- 
viously described by [35] and those of the thermal reaction model developed in the present paper to predict the conversion of $\mathrm{HI}$ into NHI in the meat.

Meat is a multi-composite structure and juice expulsion during cooking is the result of complex phenomena. When the meat is heated, water begins to unbound to proteins and myofibers and collagenous tissues contract. This thermal contraction exerts a strong mechanical pressure on the juice located inside the fibers and between the different muscle bundles. This mechanical pressure expels the juice from the meat through multiple channels of different sizes that pass in between the fibers and in between the primary and the secondary bundles [36] [37]. This migration of juice under mechanical stress is anisotropic and leads to a reduction of the meat piece volume. Advanced heat-mass transfer models have been developed in the literature to predict the expelling of juice under mechanical pressure [38] [39]. However, they do not consider the multi-composite nature of the beef meat piece, the flowing of juice into channels of different sizes, etc. Thus, discrepancies remain between the predictions of these models and the water content profiles measured in the meat. Faced with this situation we have decided to describe juice expelling by an observation-based model using a simple relation and a few parameters, to have enough time: 1) to test it under different cooking situations, and 2) to determine the kinetics of the reactions responsible for the variations of the meat nutritional qualities. Our juice transfer model [35], is based on experimental observations and on the assumptions that: 1) the unbounding of water from proteins and the pressure effects exerted by collagen tissues on juice migration depend on the spatial variations of temperature inside the meat, 2) the water concentration at one point of the meat (expressed on a dry matter basis) can never be less than the equilibrium water content calculated from the maximum temperature reached that point of the meat, and 3) effects of crust formation on juice expelling can be neglected.

Model's parameters are given in Table 2. The variation of the concentration of Fe in meat ( $C_{\mathrm{Fe}}$ being either $C_{\mathrm{HI}}$ or $C_{\mathrm{NHI}}$ ) as the function of time depended on both juice expulsion and thermal conversion through the two mathematical terms $\left(\frac{\partial C_{\mathrm{Fe}}}{\partial t}\right)_{\text {exp }}$ and $\left(\frac{\partial C_{\mathrm{Fe}}}{\partial t}\right)_{\text {conv }}$ :

$$
\frac{\partial C_{\mathrm{Fe}}}{\partial t}=\left(\frac{\partial C_{\mathrm{Fe}}}{\partial t}\right)_{\text {exp }}+\left(\frac{\partial C_{\mathrm{Fe}}}{\partial t}\right)_{\text {conv }}
$$

A conduction model is used to calculate the space-time variation of temperature in the meat (Equation (2), Table 3). This result is used to calculate the variations of the concentrations through Equations (2)-(6) under the hypotheses detailed in Table 3. Our juice transfer model was based on a reaction-like equation. There was no water transport equation, and the effect of the water migration on the spatial water content in the meat was indirectly considered by varying the reaction rate constant, not only as a function of temperature but also as the function of the distance from the surface [35]. 


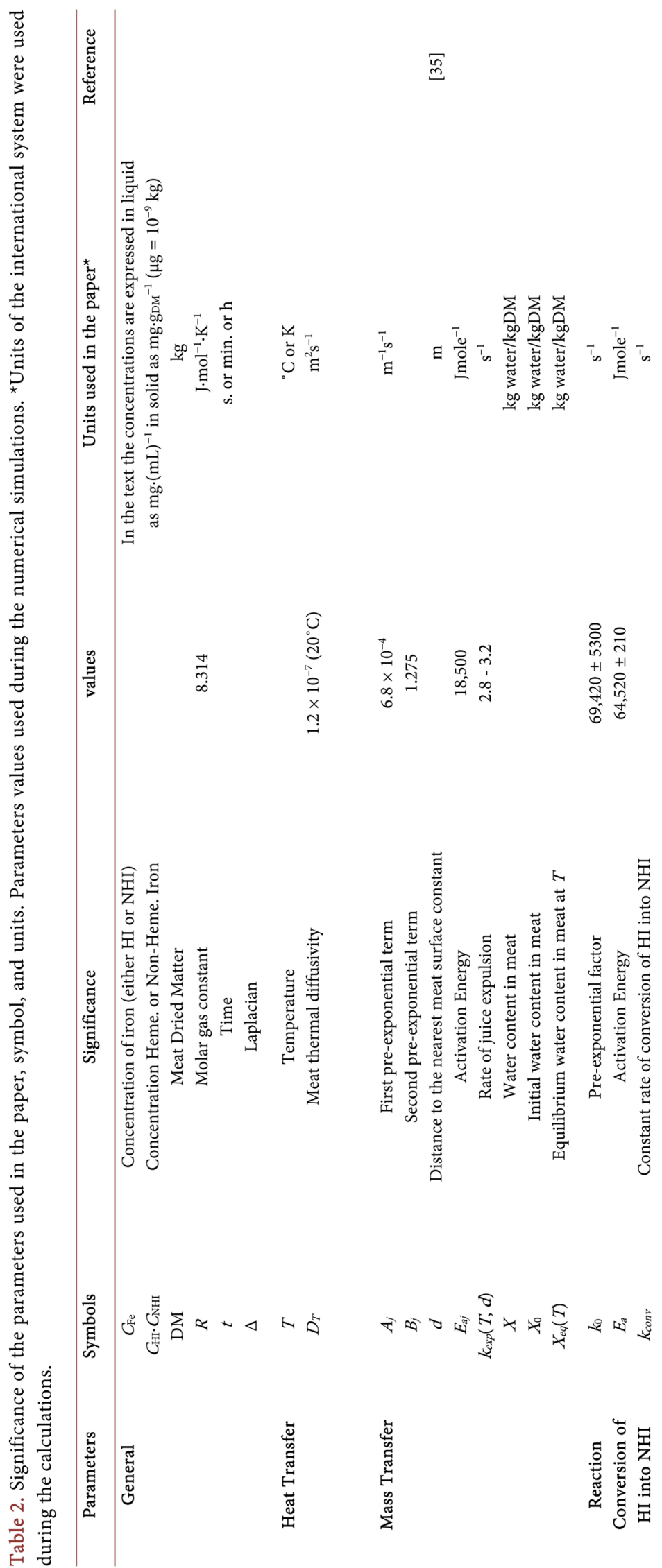


Table 3. Assumptions and equations used in the combined model.

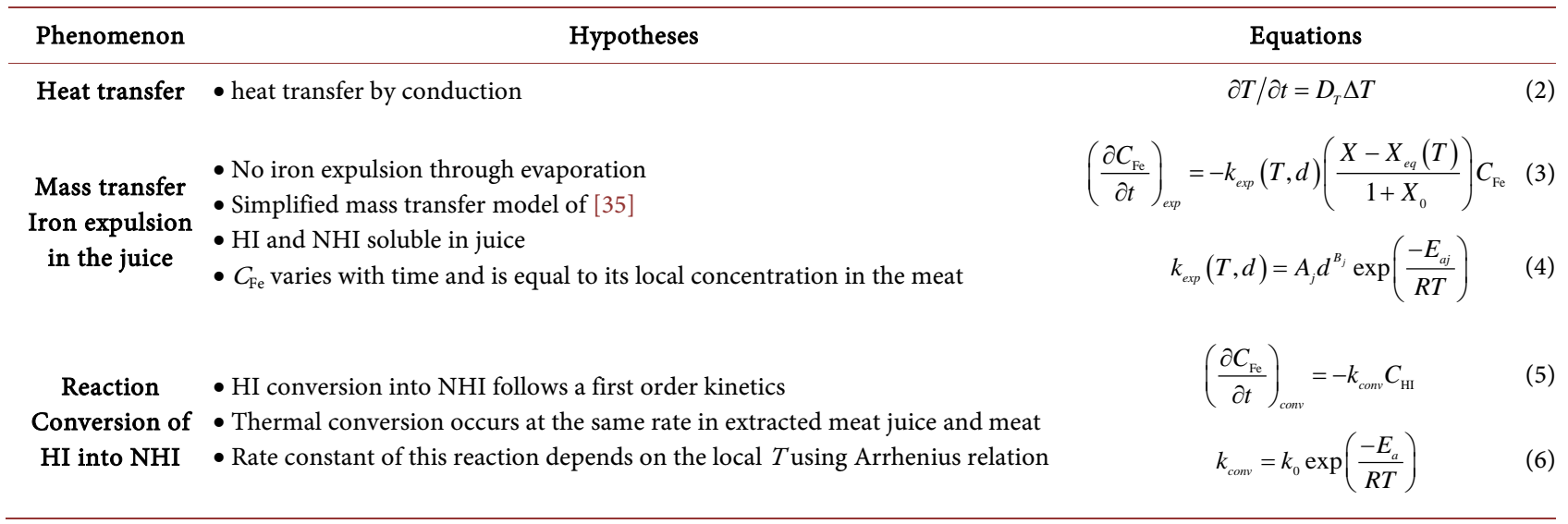

Using the equations of Table 3 the Equation (1) became:

$$
\frac{\partial C_{\mathrm{Fe}}}{\partial t}=-k_{\text {exp }}(T, d)\left(\frac{X-X_{e q}(T)}{1+X_{0}}\right) C_{\mathrm{Fe}}-e k_{\text {conv }} C_{\mathrm{HI}} \text {, while } X>X_{e q}(T)
$$

with e being equal to +1 for $C_{\mathrm{HI}}$ and to -1 for $C_{\mathrm{NHI}}$. Juice expulsion was stopped as soon as $X=X_{e q}(T)$ then the variations of $C_{\mathrm{HI}}$ and $C_{\mathrm{NHI}}$ were only due to thermal conversion. The parameters values of the heat-mass transfer model detailed in Table 2 are those used in [35].

Equations (2), (4), (6) and (7) constituted the combined system to be solved to obtain the space-time variations of $C_{\mathrm{Fe}}$ in the meat. This combined transfer-reaction model was implemented in COMSOL Multiphysics ${ }^{\circledR} 3.4$, which solves systems of nonlinear differential equations by the finite element method. When the cooking methods and conditions were closed to that of our previous paper as for immersion cooking, stewing, roasting under pure steam conditions, or mixed air-steam conditions, or even under dry air cooking for roast beef meat piece, Neumann boundary conditions were used in the heat transfer model and the values of the heat transfer coefficients, and the other parameters, were those used previously under the same conditions [35]. For different air velocities and/or more important radiation conditions an effective transfer coefficient was calculated as in [40] [41]. In the case of contact heating, a $100^{\circ} \mathrm{C}$ Dirichlet boundary condition was simply applied on the contacting surface.

The numerical procedure and numerical mesh were the same as in [35] [42]. Spatial $C_{\mathrm{Fe}}$ values calculated by the model in the meat cubes were averaged at each cooking time to obtain the average concentration values in a given volume $\bar{C}$; these calculated values were compared afterward to the iron content measured in the same volume and at the same time.

The predictions of the total quantity of juice expelled from the meat by the model had been compared to experimental measurements, in a previous paper, for beef meat cubes and cuboids heated in water bath from $50^{\circ} \mathrm{C}$ up to $90^{\circ} \mathrm{C}$ [35]. The transfer model was also tested for steaks and roasts of different dimensions cooked in an oven under $10 \%$ steam injection or pure steam injection condi- 
tions, and under dry air conditions at a temperature of $90^{\circ} \mathrm{C}$ or of $250^{\circ} \mathrm{C}$. Despite its simplicity, the transfer model proved to be able to predict the mass of juice that was expelled from the meat under all these situations [35]. In the case of contact, the model had not been validated and the calculated values were considered as more approximate than those obtained under the other cooking situations.

The parameters of the reaction of conversion of $\mathrm{HI}$ into NHI $\left(k_{0}\right.$ and $\left.E_{a}\right)$ were the only one which had not been determined in [35]. Thus, they have been identified in the present paper from the experiments performed in the extracted meat juice by minimizing the sum of squared differences between the experimental and the calculated results.

\subsection{Estimations of the Iron Supply Related to Beef Meat Consumption}

The amounts of the HI and NHI contents in the cooked meat were assumed to result from a $100 \mathrm{~g}$ raw meat portion completely eaten by the consumer. This is to reflect some typical French meals when beef meat is consumed without other important sources of iron coming from plant foods. As the French consume only $46 \mathrm{~g}$ of butcher's meat per day on average this typical French meal did not occur every day anymore. The potential amount of iron absorbed by the consumer (PAIA) during these typical French meals was calculated as followed:

$$
[\text { PAIA }]=[\text { HIweight } \times \text { HIabs }]+[\text { NHIweight } \times \text { NHIabs }]
$$

The absorbed proportion of HI and NHI: HIabs and NHIabs, were chosen to be equal to 0.25 and 0.05 respectively. These values are means of what is reported in the literature for both iron forms estimated for many diets in various experimental conditions for humans with normal iron status [8] [9] [12] [15]. The PAIA was calculated here as mg of absorbed iron. It is widely accepted that adult men and menstruating women must absorb 0.9 and $1.6 \mathrm{mg}$ iron per day, respectively, to cover their iron requirements [43] [44]. The ratio between the PAIA and these two values of 0.9 and 1.6 indicated the contribution in percentage of each meat portion of these typical French meals in covering the daily requirement for an adult man and a menstruating woman. The PAIA was calculated for 2 beef muscles: longissimus thoracis (LT), and semimembranosus (SM), as the former is used for grilling and roasting, while the latter is an example of a tougher muscle that can be braised, stewed or even pressure cooked. HI and $\mathrm{NHI}$ contents in $100 \mathrm{~g}$ of the raw muscles were respectively: $1.56 \pm 0.23 \mathrm{mg}$ and $0.66 \pm 0.06 \mathrm{mg}$ for LT, $1.74 \pm 0.22$ and $0.64 \pm 0.07 \mathrm{mg}$ for SM.

\section{Results and Discussion}

Model Equations (1)-(7) were applied for all the types of cooking methods considered in this paper; these equations are uncompleted when the heating is due to microwave treatments (not considered in this paper). The model parameters connected to the heat and mass transfers inside the meat had been determined in 
a previous study [35]. Thus, the only unknown parameter values were those of $k_{0}$ and $E_{a}$ which were determined from the HI kinetics measured in the heated meat juice. Model predictions in meat were validated by comparing calculations to the measurements obtained in meat cubes heated in the water bath. Finally, the boundary conditions were adapted to predict the variations of the $\mathrm{HI}$ and NHI contents in meat pieces cooked under different cooking methods and time-temperature conditions than in the water bath.

\subsection{Kinetics of the Thermal Conversion of $\mathrm{HI}$ into NHI in Meat Juice}

When the temperature of the bath ranged from $50^{\circ} \mathrm{C}$ to $98^{\circ} \mathrm{C}$, the kinetics of temperature in the test tube was fast and the juice temperature in the tube reached $90 \%$ of the bath temperature in less than $10 \mathrm{~min}$. When the oil bath temperature was $120^{\circ} \mathrm{C}$, the juice temperature kinetics was slower and $20 \mathrm{mi}$ nutes were needed for the juice temperature in the test tube to reach $90 \%$ of the bath temperature.

The non-cooked rehydrated juice contained $10.2 \%$ of $\mathrm{DM}$ and $18.7 \pm 0.7 \mu \mathrm{g}$ total iron/mL. HI represented $15.1 \pm 0.3 \mu \mathrm{g} / \mathrm{mL}$, accounting for $80.6 \% \pm 3.8 \%$ of the total iron content. At a bath temperature of $50^{\circ} \mathrm{C}$, the $\mathrm{HI}$ content in the juice was constant throughout the heating experiment. At $60^{\circ} \mathrm{C}$, it was still $92 \%$ of its initial value after $300 \mathrm{~min}$ of heating. Over $60^{\circ} \mathrm{C}$, the decrease of the HI content in the juice was much higher with only $4 \%$ of its initial value remaining after 300 min of heating at $120^{\circ} \mathrm{C}$ (Figure 2). The variation in $\mathrm{HI}$ content in the juice during heating was calculated using the Equations (5), (6). The values of $k_{0}$ and $E_{a}$ were determined by minimizing the differences between the experimental and calculated results, either using the water bath temperature, or the temperature measured in the test tube. No significant differences in the determination of $k_{0}$ and $E_{a}$ and the prediction of the experimental data were observed when the bath temperature ranged from $50^{\circ} \mathrm{C}$ to $98^{\circ} \mathrm{C}$, while test tube temperature measurements were required to accurately predict $\mathrm{HI}$ conversion when the bath temperature was $120^{\circ} \mathrm{C}$. The $k_{0}$ and $E_{a}$ values determined using test tube measurements were $69,420 \pm 5300 \mathrm{~s}^{-1}$ and $64,520 \pm 210 \mathrm{Jmole}^{-1}$, respectively. The average difference between measurements and predictions using these parameter values was $0.7 \mu \mathrm{g} / \mathrm{ml}$ (Figure 2). The decrease of the HI content at all the bath temperatures was indeed associated with a simultaneous increase of the NHI content in the juice. The analyses of these simultaneous variations, illustrated in Figure 3 for the $120^{\circ} \mathrm{C}$ treatment, were used to check that we were able to accurately monitor the conversion of HI into NHI. Literature data on the conversion of HI into NHI are generally measured in the meat for product temperature of less than $100^{\circ} \mathrm{C}$ and heating durations of less than one hour [28] [45]. This explains why this conversion is most often limited (less than $20 \%$ of the initial HI content) which is consistent with our results (conversion of $\mathrm{HI}$ into NHI during 1 hour of heating at $98^{\circ} \mathrm{C}$ is about $20 \%$ in Figure 2 ). 


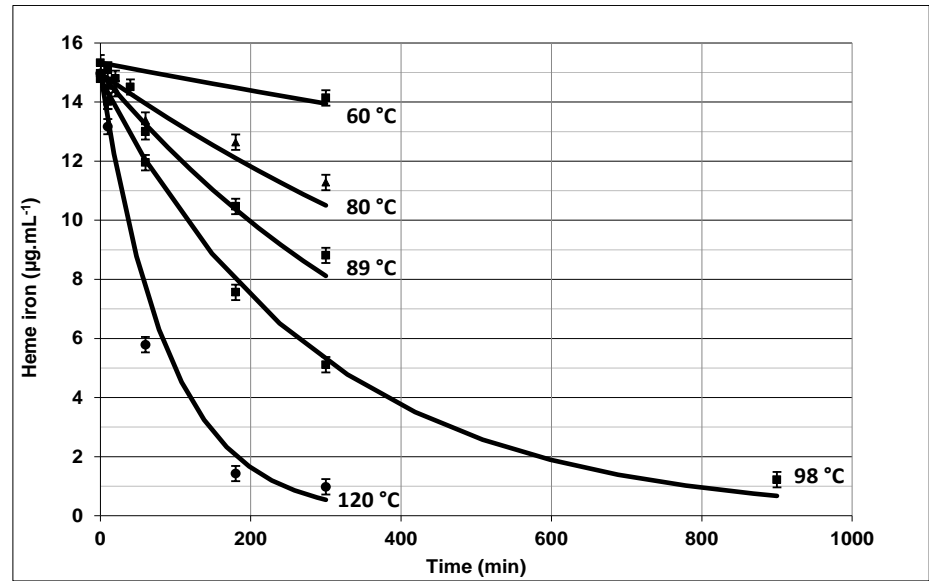

Figure 2. Kinetics of the decrease of heme iron (HI) due to its conversion into non-heme iron (NHI) in juice extracted from SM muscle and heated at different temperatures (symbols). Comparison of these measurements with the values calculated using Equations (5) and (6) with $k_{0}=69,420 \mathrm{~s}^{-1}$ and $E_{a}=$ $64,520 \mathrm{Jmole}^{-1}$ (full lines). For small SD, error bars can be hidden by the size of the dots. During the experiments, the heating of the juice was continued well beyond the usual cooking durations to be able to test the robustness and accuracy of the numerical model under these longest conditions.

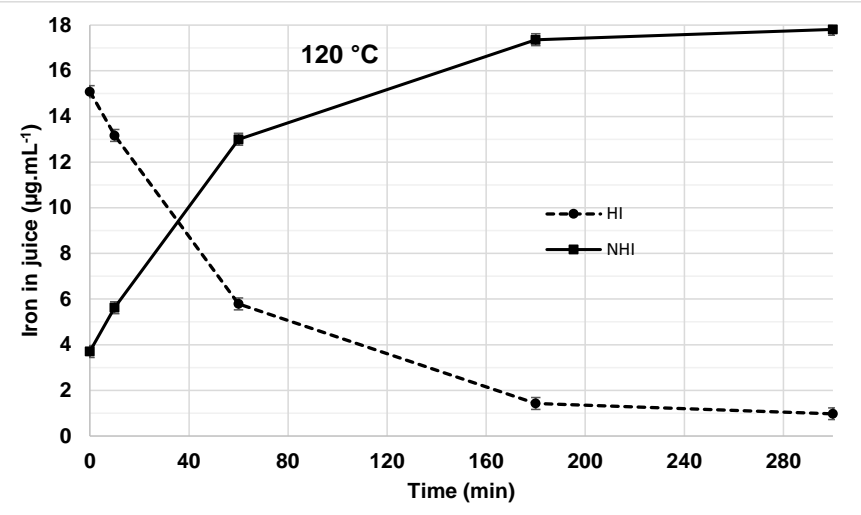

Figure 3. Measured time-related variations of $\mathrm{HI}$ and $\mathrm{NHI}$ in juice extracted from SM muscle and heated at $120^{\circ} \mathrm{C}$ (lines are not predicted values but just connections between the measured points). For small SD, error bars can be hidden by the size of the dots.

\subsection{Use of the Transfer-Reaction Model to Analyze Iron Variations for the Meat Cubes Heated in Water Bath}

The values calculated from Equations (5) (6) $\left(k_{0}\right.$ being $69,420 \mathrm{~s}^{-1}$ and $E_{a} 64,520$ $\mathrm{Jmole}^{-1}$ ) were added to those issued from the heat-mass transfer model (Equations (2) to (4)) to predict the variations of the local HI and NHI contents in the heated meat cubes due to both thermal conversion and juice expulsion. Temperature gradients inside the $3 \mathrm{~cm}$ sided cube were high only during the first 30 min, as afterward the temperature could be considered as homogenous within it [35] [46]. The raw meat used during the experiments on the $3 \mathrm{~cm}$ side cubes cut from the LT muscle contained $2.54 \pm 0.03 \mathrm{mg}$ total iron $/ 100 \mathrm{~g}$ raw meat and 1.81 $\pm 0.02 \mathrm{mg} \mathrm{HI}$, which represents $71.0 \% \pm 0.9 \%$ of the total iron. These values were 
close to those found in the literature which showed that $\mathrm{HI}$ in beef is composed of between $60 \%-80 \%$ total iron [23] [45] [47]. In the following iron content is expressed for our results on a meat dry matter basis to consider both the variations due to juice expulsion and to thermal conversion.

As expected, the HI content measured in the meat tended to decrease with time; this decrease was more pronounced at $80^{\circ} \mathrm{C}$ than at $60^{\circ} \mathrm{C}$ (Figure 4). A further increase of the water bath temperature up to $95^{\circ} \mathrm{C}$ led to more complex kinetics. The measured $\mathrm{HI}$ content in the meat at $95^{\circ} \mathrm{C}$ decreased from 0 to 30 min then remained steady between 30 and $60 \mathrm{~min}$ and then decreased again between 60 and $300 \mathrm{~min}$.

The HI kinetics predicted by the model at $60^{\circ} \mathrm{C}$ and $80^{\circ} \mathrm{C}((1)$ and (2) in Figure 4) agreed with the measurements at these two temperatures whereas the calculations underestimated the $\mathrm{HI}$ content in the meat at $95^{\circ} \mathrm{C}$ (curve 3 in Figure 4). It was possible during the calculations to separate the part of the HI loss due to juice expulsion from that which came from HI conversion into NHI (first and second terms in Equation (7)). These separate calculations show that the decrease of $\mathrm{HI}$ in the $3 \mathrm{~cm}$ side cubes was mainly due to juice expulsion during the first $30 \mathrm{~min}$ whatever the heating temperature, and totally due to the conversion of $\mathrm{HI}$ into NHI after $60 \mathrm{~min}$ of heating at $95^{\circ} \mathrm{C}$. The fact that the combined transfer-reaction model $(1-7)$ was able to predict the kinetics obtained at $60^{\circ} \mathrm{C}$ and $80^{\circ} \mathrm{C}$ supports the assumptions on which the model relied for these two temperatures, i.e. the fact that $\mathrm{HI}$ was expelled in the juice at a concentration proportional to its local concentration in the meat while part of the HI remaining in the meat was converted into $\mathrm{NHI}$ at a rate which corresponded to the conversion observed in the juice and described mathematically by Equations ( 5 , 6) (Figure 2). The failure of the model during the heat treatment after $60 \mathrm{mi}$ nutes at $95^{\circ} \mathrm{C}$ was due to a phenomenon not previously considered in the model, namely the loss of heme protein solubility which was visually observed by [26], by a change of color of the expelled juice that occurred between $77^{\circ} \mathrm{C}$ and $97^{\circ} \mathrm{C}$. Like us, these authors also measured a higher $\mathrm{HI}$ content (on DM basis) in the meat after $1 \mathrm{~h}$ of heating at $97^{\circ} \mathrm{C}$ than after $1 \mathrm{~h}$ at $80^{\circ} \mathrm{C}$. This stopping of $\mathrm{HI}$ decreases in the meat after $30 \mathrm{~min}$ at $95^{\circ} \mathrm{C}$, clearly visible in our measured kinetics, indicated heme protein coagulation which occurred during heating (Figure 4). After $1 \mathrm{~h}$ of heating, the variations of the $\mathrm{HI}$ content in the meat were due only to the thermal conversion of HI into NHI. Considering the experimental errors, the NHI variations in the meat were the same for the three water bath temperatures $\left(60^{\circ} \mathrm{C}, 80^{\circ} \mathrm{C}, 95^{\circ} \mathrm{C}\right)$. An average of these variations is given in Figure 5. NHI content decreased during the first $30 \mathrm{~min}$, remained steady between 30 - $60 \mathrm{~min}$ and then showed a moderate increase (Figure 5). The model was used to calculate the expulsion of $\mathrm{NHI}$ in the juice and its formation through the conversion of $\mathrm{HI}$ which remained in the meat into NHI. The predictions calculated at $60^{\circ} \mathrm{C}$ and $80^{\circ} \mathrm{C}$ reproduced these temporal variations which reflect the slowing down and then stopping of the $\mathrm{HI}$ and $\mathrm{NHI}$ expelled in the juice due to the end of meat protein contraction, and of the conversion of the HI 
content which remained in the meat into NHI, which continued after the expulsion of the juice (Figure 5). The calculated quantity of NHI expelled in the juice and the conversion rate of $\mathrm{HI}$ into NHI were different at $60^{\circ} \mathrm{C}$ and $80^{\circ} \mathrm{C}$, but their balances were similar, leading to similar NHI curves. The similarity of the NHI kinetics measured at $95^{\circ} \mathrm{C}$ with that measured at $60^{\circ} \mathrm{C}$ and $80^{\circ} \mathrm{C}$, suggested that the balance between NHI expulsion and formation was also similar above $80^{\circ} \mathrm{C}$.

The HI/NHI ratio was 2.0 in the raw meat and its decrease was different between $60^{\circ} \mathrm{C}$ and $80^{\circ} \mathrm{C}$. The decrease was less pronounced at $60^{\circ} \mathrm{C}$ than at $80^{\circ} \mathrm{C}$ where it reached 1.5, 1.1 and 0.9 after $1 \mathrm{~h}, 2 \mathrm{~h}$ and $5 \mathrm{~h}$ of heating, respectively. [26], who measured a ratio of 2.0 in raw meat, found a ratio of 1.2 and 1.1 after 1 $\mathrm{h}$ of heating at $77^{\circ} \mathrm{C}$ and $97^{\circ} \mathrm{C}$, respectively (Table 1).

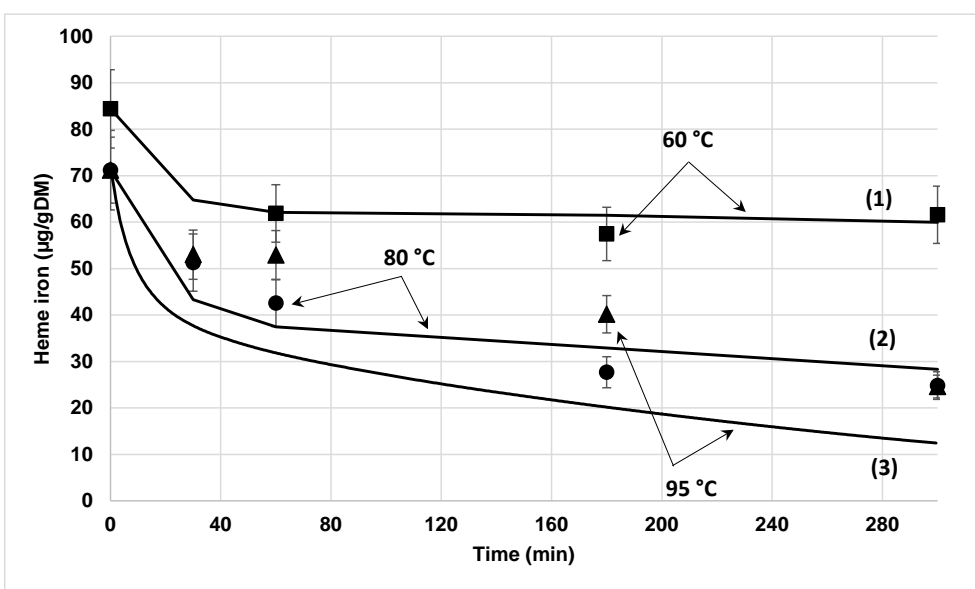

Figure 4. Comparison between the time-course of the $\mathrm{HI}$ concentration measured in the $3 \times 3 \times 3 \mathrm{~cm}$ meat cubes immersed in the water bath at $60^{\circ} \mathrm{C}$, $80^{\circ} \mathrm{C}$ or $95^{\circ} \mathrm{C}$ (square, circle and triangle symbols respectively) and the values predicted by our combined transfer-reaction model at the same water bath temperatures: $60^{\circ} \mathrm{C}(1$, line $), 80^{\circ} \mathrm{C}(2$, line $)$ and $95^{\circ} \mathrm{C}(3$, line $)$.

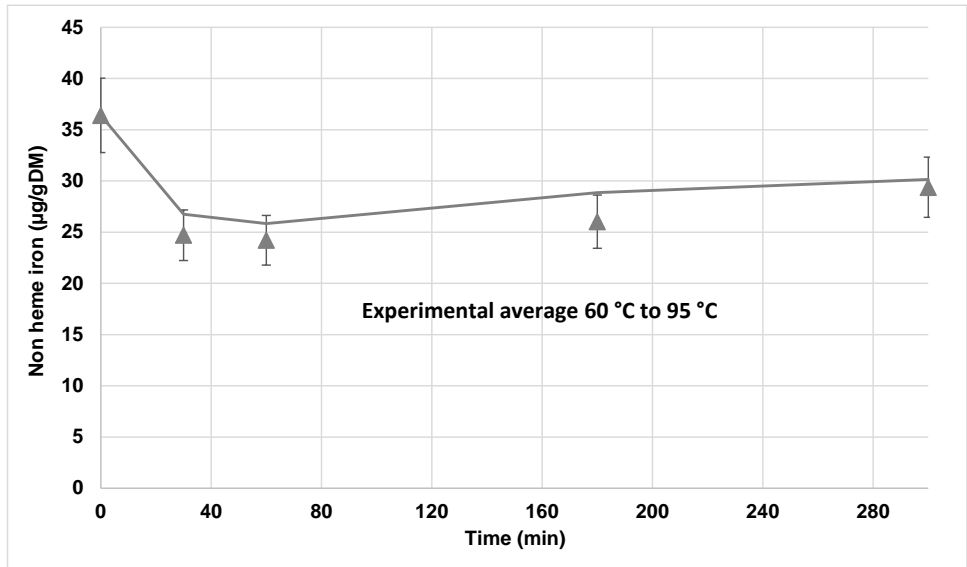

Figure 5. Comparison between the time-course of the average NHI concentration measured in the $3 \times 3 \times 3 \mathrm{~cm}$ meat cubes immersed in the water bath measured at $60^{\circ} \mathrm{C}, 80^{\circ} \mathrm{C}$ and $95^{\circ} \mathrm{C}$ (symbols) or predicted by the transfer-reaction model at $60^{\circ} \mathrm{C}$ and $80^{\circ} \mathrm{C}$ and then averaged. 


\section{Effects of Cooking Mode and Time-Temperature Conditions on the Iron Supply Related to Meat Consumption}

The combined transfer-reaction model was used to predict the variations of $\mathrm{HI}$ and NHI and their potential nutritional impacts for meat pieces cooked according to the most widely culinary practices in France (microwave cooking being excluded here). The equations of the model and the values of the parameters were those of Table 2 and Table 3. HI expelling was stopped as soon as the average temperature of the meat exceeded $80^{\circ} \mathrm{C}$ to consider the effect of heme protein coagulation. The boundary conditions and the sample dimensions were changed according to the type of cooking methods and meat cuts commonly used in practice. Details on the application of the boundary conditions can be found in [35] [40] [41] [42]. In practice, for the same cooking method, the equipment can be different and a range of boundary conditions has to be applied to consider these variations. Since the dimensions of the sample can also be different this leads to a range of juice loss and cooking yield as shown in Table 4. This table is only a selection of some of the results obtained during a wider set of calculations, the purpose of this selection being to give an order of magnitude of the nutritional impacts of the different cooking modes and time-temperature conditions used in France. In the following, the iron expelled from the meat piece into the juice was supposed to be lost for the consumer. However, it should be noticed that in some recipes part of the expelled juice and its iron content is consumed.

HI and NHI losses can be calculated from the values reported in Table 4 by comparing the initial $\mathrm{HI}$ and NHI contents in the raw meat to the contents in the meat pieces subjected to different cooking conditions; the losses being expressed as percentages of the initial HI or NHI contents for a $100 \mathrm{~g}$ portion of the raw meat. Unsurprisingly, the calculations showed that the shortest cooking conditions (less than $5 \mathrm{~min}$ ) and the lowest cooking temperatures (less than $55^{\circ} \mathrm{C}-60^{\circ} \mathrm{C}$ ) lead to the smallest iron losses. For the steaks cooked rare, the losses are on the average $12 \%$ of the initial $\mathrm{HI}$ or NHI content in the raw meat. These variations can be compared to the animal-to-animal variability assessed by the ratio of the standard deviation of the iron measured in the same raw muscle for different animals to the average iron content measured on all the animals. Under the shortest cooking conditions, animal variability was of the same order of magnitude as the variation of iron due to cooking. The values issued from ( 3 , 4 ) and from $(5,6)$ were also used to compare the relative contribution of expulsion and conversion to the global losses. This comparison shows that under the shortest cooking conditions almost all the HI losses were due to juice expulsion. Roasting bigger meat pieces at higher temperatures increases irons losses and conversion of HI into NHI and thus decreases the contribution of the meat portion to the PAIA. For example, such a portion of meat, issued from a big very well-done roast contributes only to $29 \%-37 \%$ and $16 \%-21 \%$ of the PAIA for an 
Table 4. Nutritional impacts of cooking on the estimated Potential Amount of Iron Absorbed (PAIA) and on the contribution of $100 \mathrm{~g}$ of raw beef meat cooked in different ways to the daily iron requirement for adult man $(0.9 \mathrm{mg} / \mathrm{day}) \mathrm{and} \mathrm{men}$ strual woman $(1.60 \mathrm{mg} /$ day). These values have been estimated from model calculations under the different assumptions detailed in the text of the paper. When the meat was cut in steaks or in roasts calculated results depended on the dimensions of the meat pieces. The values given in this table have been calculated for a steak of $20 \times 70 \times 70$ millimeters and for a $60 \times 60$ $\times 110 \mathrm{~mm}$ meat roast. PAIA was estimated considering $\mathrm{HI}$ and NHI absorption rate were $25 \%$ and $5 \%$ respectively. The formula was PAIA $=(0.25 \times \mathrm{HI}$ weight $+0.05 \mathrm{NHI}$ weight $)$ for each cooked or raw meat, in this formula, NHI and HI weights were expressed in $\mathrm{mg}$.

\begin{tabular}{|c|c|c|c|c|c|c|c|}
\hline \multirow[t]{2}{*}{ Muscles } & \multirow[t]{2}{*}{ Cooking methods } & \multirow[t]{2}{*}{$\begin{array}{l}\text { Cooking } \\
\text { yield (\%) }\end{array}$} & \multirow[t]{2}{*}{$\begin{array}{c}\mathrm{HI} \text { in meat } \\
\text { portion } \\
(\mathrm{mg} / 100 \mathrm{~g} \text { raw meat })\end{array}$} & \multirow[t]{2}{*}{$\begin{array}{c}\text { NHI in meat } \\
\text { portion } \\
(\mathrm{mg} / 100 \mathrm{~g} \text { raw meat })\end{array}$} & \multirow[t]{2}{*}{$\begin{array}{c}\text { PAIA } \\
(\mathrm{mg} / 100 \mathrm{~g} \\
\text { raw meat })\end{array}$} & \multicolumn{2}{|c|}{$\begin{array}{l}\text { Daily iron } \\
\text { requirements from } \\
100 \mathrm{~g} \text { of raw meat }\end{array}$} \\
\hline & & & & & & Adult man & Adult woman \\
\hline \multirow{5}{*}{$\begin{array}{l}\text { Longissimus } \\
\text { thoracis }\end{array}$} & Raw & 100 & 1.60 & 0.70 & 0.43 & 47 & 27 \\
\hline & Steak grilled rare & $90-95$ & 1.40 & 0.60 & 0.38 & 42 & 24 \\
\hline & Grilled or roasted rare & $80-85$ & 1.20 & 0.60 & 0.34 & 37 & 21 \\
\hline & $\begin{array}{c}\text { Grilled or roasted } \\
\text { welldone served hot }\end{array}$ & $70-75$ & 1.10 & 0.60 & 0.29 & 32 & 18 \\
\hline & $\begin{array}{c}\text { Big roast very } \\
\text { welldone or served cold }\end{array}$ & $65-70$ & 0.90 & 0.50 & 0.26 & 29 & 16 \\
\hline \multirow{3}{*}{$\begin{array}{l}\text { Semi-membranosus } \\
\text { as an example of a } \\
\text { tougher muscle }\end{array}$} & Raw & 100 & 1.70 & 0.64 & 0.46 & 51 & 29 \\
\hline & Stewed or Braised & $60-70$ & 0.90 & 0.39 & 0.25 & 28 & 16 \\
\hline & $\begin{array}{c}\text { Under-pressure }> \\
115^{\circ} \mathrm{C}\end{array}$ & $50-70$ & $0.30-0.50$ & $0.30-0.50$ & $0.10-0.14$ & $11-15$ & $6-9$ \\
\hline
\end{tabular}

adult man and woman, respectively (Table 4). In this case, the degree of doneness and the size of the meat piece can affect the contribution of food portions to daily iron requirement more than the biological variability between animals.

In traditional French culinary practice some pieces of beef meat cut from muscles, or part of muscles known to be tougher, can be braised and/or stewed at temperatures close to $80^{\circ} \mathrm{C}$ for more than one hour to ensure tenderness. These conditions can increase both the iron loss into the juice and the conversion of HI into NHI. An important decrease in both HI and NHI content in meat was observed, reducing the PAIA and the contribution of meat portions to the daily iron requirement. Thus, one hour of stewing an SM portion decreased the amounts of both $\mathrm{HI}$ and $\mathrm{NHI}$ in the meat portion: $-47 \%$ and $-39 \%$ respectively. PAIA was reduced by $45 \%$. The contribution of a stewed meat portion to the daily iron requirement of an adult man and an adult woman fell to $28 \%$ and $16 \%$, respectively. The decreases in both PAIA and the contribution to DIR can be higher when meat is stewed for several hours due to the ongoing conversion of $\mathrm{HI}$ to NHI.

The model was also used to assess the variation of $\mathrm{HI}$ and $\mathrm{NHI}$ contents during a one-hour pressure cooking at $118^{\circ} \mathrm{C}$ (the highest temperature that a domestic pressure cooker can reach at 1.8 bar). In that case, the average meat temperature raised well above $80^{\circ} \mathrm{C}$, leading to the coagulation of heme protein which stopped the expelling of $\mathrm{HI}$ into the juice. Heme protein coagulation was 
not included in the model which rendered the model more limited in that case. However, this phenomenon was simulated in the calculations by stopping the flow of iron in the juice as soon as the meat average temperature exceeded $80^{\circ} \mathrm{C}$. Hence, the quantity of $\mathrm{HI}$ expelled in the juice depended on the time needed for the meat piece to reach $80^{\circ} \mathrm{C}$, which was connected to the pressure increase in the cooker and the size of the meat piece. The differences in time needed to reach $80^{\circ} \mathrm{C}$ have led to the different values of the cooking yield given in Table 4 (either $50 \%$ or $70 \%$ ). Afterward, the meat temperature reached $118^{\circ} \mathrm{C}$ where it stayed during the rest of the cooking, leading to the conversion of $\mathrm{HI}$ into NHI. In the pressure-cooking situation, the calculations showed that the amounts of both $\mathrm{HI}$ and NHI fell dramatically: $-76 \%$ and $-38 \%$, respectively. Consequently, the PAIA was reduced by about $45 \%$ and the contributions of the SM meat portion to the daily iron requirement of an adult man and an adult woman were low: $11 \%-15 \%$ and $6 \%-8 \%$, respectively.

Previous results should be considered in epidemiological studies on nutrition for certain sensitive populations, notably women during puberty, menstruation, and pregnancy, and elderly persons of both genders, which can have recourse to the most impacting cooking methods. It is well known as a general trend that in Western countries these populations tend to eat less meat while their iron needs can be the same or even higher than those of adult men. Using higher time-temperature cooking conditions to avoid tough meat (since tender meat is more expensive or because older people can have masticatory problems), or possible microbial safety problems, or simply for reasons of personal taste, can lead to anemia for sensitive populations if not compensated by other iron supplies. These considerations are not new but they can be better quantified and understood using the proposed modeling approach and results.

These results strongly suggest that cooking meat at low temperatures for a long time preserves heme iron content and bioavailability as illustrated by results in Figure 4. Cooking in these mild conditions could be helpful to prevent or correct iron deficiency in populations known to be specifically exposed to this problem in Western countries, such as adult women and poor and/or old people who tend to eat less meat than middle-aged men.

\section{Conclusions}

The effect of cooking on meat iron content is linked to both the loss of iron (HI and NHI) from the meat piece by juice expulsion and the conversion of $\mathrm{HI}$ into $\mathrm{NHI}$ in the meat piece. When the meat temperature was under $80^{\circ} \mathrm{C}$, HI was expelled in the juice. Above $80^{\circ} \mathrm{C}$, heme proteins coagulated and $\mathrm{HI}$ expulsion was stopped while the conversion of $\mathrm{HI}$ into $\mathrm{NHI}$ remained. Due to these phenomena, the HI/NHI ratio decreased from 2.0 when it was raw to less than 1.0 for the longest heat treatments and highest temperatures. The model was used to assess the effect of cooking on the contribution of $100 \mathrm{~g}$ of raw beef meat issued from two different muscles to the daily iron requirement for men and menstruating 
women. Shortest cooking durations and lowest heating temperatures have almost no effect on the iron supply while roasting big meat pieces, braising and stewing at higher temperatures decreased this contribution. The lowest contribution of meat to iron supply was found for under-pressure cooking at temperatures above $100^{\circ} \mathrm{C}$, often used in practice to avoid tough meat or possible microbial safety problems. During our calculations, the iron expelled from the meat piece into the juice was supposed to be lost for the consumer. However, it should be noticed that in certain recipes (stews or casseroles) part of this released iron will be consumed, thus increasing the iron supply.

The paper was focused on iron supply and thus on the nutritional consequences of cooking. However, the present results and model can also help to better quantify the effect of cooking on the sensorial and toxicological properties of cooked meat due to oxidation if they are associated with more complex reaction schemes [48]. All these works will contribute to the design of tailor-made diets, containing meat, to ensure sensorial pleasure, balanced nutrition, and optimal health.

\section{Acknowledgements}

Authors wish to thank the French meat information center (CIV) for funding.

\section{Conflicts of Interest}

The authors declare no conflicts of interest regarding the publication of this paper.

\section{References}

[1] Geissler, C. and Singh, M. (2011) Iron, Meat and Health. Nutrients, 3, 283-316. https://doi.org/10.3390/nu3030283

[2] McLean, E., Cogswell, M., Egli, I., Wojdyla, D. and de Benoit, B.M. (2009) Worldwide Prevalence of Anemia, WHO Vitamin and Mineral Nutrition Information System 1993-2005. Public Health Nutrition, 12, 444-454. https://doi.org/10.1017/S1368980008002401

[3] Hercberg, S., Preziosi, D. and Galan, P. (2001) Iron Deficiency in Europe. Public Health Nutrition, 4, 537-545. https://doi.org/10.1079/PHN2001139

[4] Rasmussen, K. (2001) Is There a Causal Relationship between Iron Deficiency or Iron Deficiency Anemia and Weight at Birth, Length of Gestation and Perinatal Mortality? Journal Nutrition, 131, 590S-601S. https://doi.org/10.1093/jn/131.2.590S

[5] Pollit, E. (1993) Iron Deficiency and Cognitive Function. Annual Reviews in Nutrition, 13, 521-537. https://doi.org/10.1146/annurev.nu.13.070193.002513

[6] Scholz, B., Gross, R. and Sastroamidjojo, S. (1997) Anemia Is Associated with Reduced Productivity of Women Workers Even in Less Physically Strenuous Tasks. British Journal Nutrition, 77, 147-157. https://doi.org/10.1017/S0007114500002877

[7] Hurrell, R. (1997) Bioavailability of Iron. European Journal Clinical Nutrition, 51, S4-S8.

[8] Hurrell, R. and Egli, I. (2010) Iron Bioavailability and Dietary Reference Values. 
American Journal Clinical Nutrition, 91, 1461S-1467S.

https://doi.org/10.3945/ajen.2010.28674F

[9] Collins, R., Harvey, L.J., Hooper, L., Hurst, R., Brown, T.J., Ansett, J., King, M. and Fairweather-Tait, S.J. (2013) The Absorption of Iron from Whole Diets: A Systematic Review. American Journal Clinical Nutrition, 98, 65-81. https://doi.org/10.3945/ajcn.112.050609

[10] Cook, J.D. and Finch, C.A. (1975) Iron Nutrition. Western Journal Medicine, 122, 474-481.

[11] Layrisse, M. and Martinez-Torres, C. (1972) Model for Measuring Dietary Iron Absorption of Heme Iron: Test with a Complete Meal. American Journal Clinical Nutrition, 25, 401-411. https://doi.org/10.1093/ajcn/25.4.401

[12] Monsen, E.R., Hallberg, L., Layrisse, M., Hegsted, M.D., Cook, J.D., Mertz, W. and Finch, C.A. (1978) Estimation of Available Dietary Iron. American Journal Clinical Nutrition, 31, 134-141. https://doi.org/10.1093/ajcn/31.1.134

[13] Layrisse, M., Martinez-Torres, C., Leet, I., Taylor, P.G. and Ramirez, J. (1984) Effect of Histidine, Cysteine, Glutathione or Beef on Iron Absorption in Humans. Journal Nutrition, 114, 217-223. https://doi.org/10.1093/jn/114.1.217

[14] South, P.K., Lei, X. and Miller, D.D. (2000) Meat Enhances Nonheme Iron Absorption in Pigs. Nutrition Research, 20, 1749-1759. https://doi.org/10.1016/S0271-5317(00)00272-4

[15] Hallberg, L. (1981) Bioavailability of Dietary Iron in Man. Annual Reviews in Nutrition, 21, 123-147. https://doi.org/10.1146/annurev.nu.01.070181.001011

[16] Fairweather-Tait, S. and Hurrell, R. (1996) Bioavailability of Minerals and Trace Elements. Nutrition Research Reviews, 9, 295-324. https://doi.org/10.1079/NRR19960016

[17] Lonnerdal, B. (2010) Alternative Pathways for Absorption of Iron from Foods. Pure Applied Chemistry, 82, 429-436. https://doi.org/10.1351/PAC-CON-09-06-04

[18] Chiplonkar, S.A. and Agte, V.V. (2006) Statistical Model for Predicting Non-Heme Iron Bioavailability from Vegetarian Meals. International Journal Food Sciences and Nutrition, 57, 434-450. https://doi.org/10.1080/09637480600836833

[19] Sarria, B., Dainty, J.R., Fox, T.E. and Fairweather-Tait, S.J. (2005) Estimation of Iron Absorption in Humans Using Compartmental Modelling. European Journal Clinical Nutrition, 59, 142-144. https://doi.org/10.1038/sj.ejcn.1602030

[20] Pretorius, B., Schönfeldt, H.C. and Hall, N. (2016) Total and Haem Iron Content in Lean Meat Cuts and the Contribution to the Diet. Food Chemistry, 193, 97-101. https://doi.org/10.1016/j.foodchem.2015.02.109

[21] Czerwonska, M. and Szterk, A. (2015) The Effect of Meat Cuts and Thermal Processing on Selected Mineral Concentration in Beef from Holstein-Friesian Bulls. Meat Science, 105, 75-80. https://doi.org/10.1016/j.meatsci.2015.03.011

[22] Schricker, B.R., Miller, D.D. and Stouffer, J.R. (1982) Measurement and Content of Non-Heme and Total Iron in Muscle. Journal Food Science, 47, 740-743. https://doi.org/10.1111/j.1365-2621.1982.tb12704.x

[23] Purchas, R.W., Simcock, D.C., Knight, T.W. and Wilkinson, B.H.P. (2003) Variation in the Form of Iron in Beef and Lamb Meat and Losses of Iron during Cooking and Storage. International Journal Food Science Technology, 38, 827-837. https://doi.org/10.1046/j.1365-2621.2003.00732.x

[24] Lombardi-Boccia, G., Martinez-Dominguez, B. and Aguzzi, A. (2002) Total Heme and Non-Heme Iron in Raw and Cooked Meats. Journal Food Science, 67, 1738-1741. 
https://doi.org/10.1111/j.1365-2621.2002.tb08715.x

[25] Leseigneur-Meynier, A. and Gandemer, G. (1991) Lipid Composition of Pork Muscle as Related to Metabolic Type of the Fibres. Meat Science, 29, 229-234. https://doi.org/10.1016/0309-1740(91)90052-R

[26] Buchowski, M.S., Mahoney, A.W., Carpenter, C.E. and Cornforth, D.P. (1988) Heating and the Distribution of Total and Heme Iron between Meat and Broth. Journal Food Science, 53, 43-45. https://doi.org/10.1111/j.1365-2621.1988.tb10174.x

[27] Purchas, R.W., Rutherfurd, S.M., Pearce, P.D., Vather, R. and Wilkinson, B.H.P. (2004) Cooking Temperature Effects on the Forms of Iron and Levels of Several Other Compounds in Beef Semitendinosus Muscle. Meat Science, 68, 201-207. https://doi.org/10.1016/j.meatsci.2004.02.018

[28] Purchas, R.W., Busboom, J.R. and Wilkinson, B.H. (2006) Changes in the Forms of Iron and in Concentrations of Taurine, Carnosine, Coenzyme $\mathrm{Q}(10)$, and Creatine in Beef Longissimus Muscle with Cooking and Simulated Stomach and Duodenal Digestion. Meat Science, 74, 443-449. https://doi.org/10.1016/j.meatsci.2006.03.015

[29] Schricker, B.R. and Miller, D.D. (1983) Effects of Cooking and Chemical Treatment on Heme and Nonheme Iron in Meat. Journal Food Science, 48, 1340-1349. https://doi.org/10.1111/j.1365-2621.1983.tb09225.x

[30] Kondjoyan, A., Kohler, A., Realini, C.E., Portanguen, S., Kowalski, R., Gatellier, P., Chevolleau, S., Bonny, J.M. and Debrauwer, L. (2014) Towards Models for the Prediction of Beef Meat Quality during Cooking. Meat Science, 97, 323-331. https://doi.org/10.1016/j.meatsci.2013.07.032

[31] Ardvidsson, P., van Boekel, M.A.J.S., Skog, A., Solyakov, A. and Gägerstad, M. (1999) Formation of Heterocyclic Amines in a Meat Juice Model System. Journal Food Science, 64, 216-221. https://doi.org/10.1111/j.1365-2621.1999.tb15868.x

[32] Hornsey, C. (1956) The Color of Cooked Cured Pork 1-Estimation of Nitric OxideHaem Pigments. Journal Food Science Agriculture, 7, 534-540. https://doi.org/10.1002/jsfa.2740070804

[33] Ahn, D.U., Wolfe, F.H. and Sim, J.S. (1993) Three Methods for Determining Non Heme Iron in Turkey Meat. Journal Food Science, 58, 289-291. https://doi.org/10.1111/j.1365-2621.1993.tb04257.x

[34] NF EN 14346 (2007) Calcul de la teneur en matière sèche par détermination du résidu sec et de la teneur en eau. AFNOR Editions.

[35] Kondjoyan, A., Oillic, S., Portanguen, S. and Gros, J.-B. (2013) Combined Heat Transfer and Kinetic Models to Predict Cooking Loss during Heat Treatment of Beef Meat. Meat Science, 95, 336-344. https://doi.org/10.1016/j.meatsci.2013.04.061

[36] Bouhrara, M., Clerjon, S., Damez, J.-L., Chevarin, C., Portanguen, S., Kondjoyan, A. and Bonny, J.-M. (2011) Dynamic MRI and Thermal Simulation to Interpret Deformation and Water Transfer in Meat during Heating. Journal of Agricultural and Food Chemistry, 59, 1229-1235. https://doi.org/10.1021/jf103384d

[37] Bouhrara, M., Clerjon, S., Damez, J.-L., Chevarin, C., Portanguen, S., Kondjoyan, A. and Bonny, J.-M. (2012) In-Situ Imaging Highlights Local Structural Changes during Heating: The Case of Meat. Journal of Agricultural and Food Chemistry, 60, 4678-4687. https://doi.org/10.1021/jf2046569

[38] Van Der Sman, R.G.M. (2007) Moisture Transport during Cooking of Meat: An Analysis Based on Flory-Rehner Theory. Meat Science, 76, 730-738. https://doi.org/10.1016/j.meatsci.2007.02.014

[39] Feyissa, A.H., Gernaey, K.V. and Adler-Nissen, J. (2013) 3D Modelling of Coupled 
Mass and Heat Transfer of a Convection-Oven Roasting Process. Meat Science, 93, 810-820. https://doi.org/10.1016/j.meatsci.2012.12.003

[40] Kondjoyan, A., Rouaud, O., McCann, M., Havet, M., Foster, A., Swain, M. and Daudin, J.D. (2006) Modelling Coupled Heat-Water Transfers during a Decontamination Treatment of the Surface of Solid Food Products by a Jet of Hot Air I. Sensitivity Analysis of the Model and First Validations of Product Surface Temperature under Constant Air Temperature Conditions. Journal of Food Engineering, 76, 53-62. https://doi.org/10.1016/j.jfoodeng.2005.05.014

[41] Kondjoyan, A., Rouaud, O., McCann, M., Havet, M., Foster, A., Swain, M. and Daudin, J.D. (2006) Modelling Coupled Heat-Water Transfers during a Decontamination Treatment of the Surface of Solid Food Products by a Jet of Hot Air II. Validations of Product Surface Temperature and Water Activity under Fast Transient Air Temperature Conditions. Journal of Food Engineering, 76, 63-69. https://doi.org/10.1016/j.jfoodeng.2005.05.015

[42] Kondjoyan, A., Portanguen, S., Duchène, C., Mirade, P.S. and Gandemer, G. (2018) Predicting the Loss of Vitamins B3 (Niacin) and B6 (Pyridoxamine) in Beef during Cooking. Journal of Food Engineering, 238, 44-53.

https://doi.org/10.1016/j.jfoodeng.2018.06.008

[43] Hercberg, S., Galan, P. and Dupin, H. (1987) Iron Deficiency in Africa. World Review Nutrition Dietetics, 54, 201-236. https://doi.org/10.1159/000415306

[44] Hallberg, L., Högdahl, A.M., Nilsson, L. and Rybo, G. (1966) Menstrual Blood Loss-A Population Study-Variation at Different Ages and Attempts to Define Normality. Acta Obstetrica Gynecologia Scandinavia, 45, 320-351.

https://doi.org/10.3109/00016346609158455

[45] Carpenter, C.E. and Clark, E. (1995) Evaluation of Methods Used in Meat Iron Analysis and Iron Content of Raw and Cooked Meats. Journal Agricultural Food Chemistry, 43, 1824-1827. https://doi.org/10.1021/jf00055a014

[46] Oillic, S., Lemoine, E., Gros, J.B. and Kondjoyan, A. (2011) Kinetic Analysis of Cooking Losses from Beef and Other Animal Muscles Heated in a Water Bath-Effect of Sample Dimensions and Prior Freezing and Ageing. Meat Science, 88, 338-346. https://doi.org/10.1016/j.meatsci.2011.01.001

[47] Bauchard, D., Chantelot, F. and Gandemer, G. (2008) Qualités nutritionnelles de la viande et des abats chez les bovins: Données récentes sur les principaux constituants d'intérêt nutritionnel. Cahiers Nutrition Diététique, 43, 1S29-S39.

[48] Oueslati, K., Promeyrat, A., Gatellier, P., Daudin, J.-D. and Kondjoyan, A. (2018) Stoichio-Kinetic Modeling of Fenton Chemistry in a Meat-Mimetic Aqueous-Phase Medium. Journal of Agricultural and Food Chemistry, 66, 5892-5900. https://doi.org/10.1021/acs.jafc.7b06007 